\title{
BACK MASSAGE PADA KUALITAS TIDUR IBU HAMIL TRIMESTER III
}

\author{
Yuli Yantina ${ }^{1}$, Nita evrianasari² \\ 1,2Program Studi DIV kebidanan Universitas Malahayati Bandar lampung \\ 1email: yyantina42@gmail.com \\ 2email nuninosa@gmail.com
}

\begin{abstract}
Background: During pregnancy, pregnant women will experience a variety of changes in reproduction that are physiological and sometimes pathological. Sleep difficulties are generally more common in early pregnancy. Then this sleepless complaint will reappear at the end of pregnancy. Persistent sleep disorders will interfere with the physical and psychological pregnant women.

Purpose of this study is to know the effect of back massage on sleep quality of trimester III pregnant women

Methods: Research type experimental research, design pre experiment designs with one group pretest posttest design. Population in this research is trimester mother III at BPM Tiara Iswantika Wonosari District of Pekalongan Regency of East Lampung year 2018, sample taken counted 29 people with purposive sampling technique. Analysis in this research use paired sample t test.

Results of statistical tests showed that the mean maternal sleep quality score on the measurement result using the Pittsburgh Sleep Quality Index (PSQI) questionnaire before (pretest) the back massage intervention was $6,28 \pm 1,461$ and after (posttest) the back massage intervention was 5, 03 $\pm 1,349$ with an mean difference of $1,241 \pm 0,739$. In result of paired sample t test showed back massage proved to have an effect on to sleep quality of pregnant woman trimester III (p-value $0,000<\alpha 0,05$ ).

Conclusion: With the results of this study is expected pregnant women can do back massage therapy to reduce tension, relax the body and improve sleep quality.

Suggestion Currently there is still no counseling related to back massage, so health workers should be able to provide back massage counseling to pregnant women because back massage has become part of supporting therapy in the health sector to improve health status, especially in improving the quality of sleep for pregnant women.
\end{abstract}

Keywords : Sleep quality, back massage

\section{ABSTRAK}

Latar Belakang: Pada masa kehamilan, ibu hamil akan mengalami berbagai perubahan pada sistrem reproduksi yang bersifat fisiologis dan terkadang bersifat patologis. Kesulitan tidur umumnya lebih banyak dialami pada awal kehamilan. Kemudian keluhan sulit tidur ini akan kembali muncul pada akhir kehamilan. Gangguan tidur yang terus menerus akan mengganggu fisik dan kejiwaan ibu hamil.

Tujuan: diketahuinya pengaruh back massage terhadap kualitas tidur ibu hamil trimester III

Metodologi: Jenis penelitian experimental research, desain pre experiment designs dengan rancangan one group pretest posttest. Populasi dalam penelitian ini adalah ibu trimester III di BPM Tiara Iswantika Wonosari Kec. Pekalongan Kab. Lampung Timur tahun 2018, sampel yang diambil sebanyak 29 orang dengan teknik purposive sampling. Analisis dalam penelitian ini menggunakan uji paired sample t test.

Hasil: uji statistik menunjukkan bahwa Rata-rata skor kualitas tidur ibu hamil pada hasil pengukuran menggunakan kuesioner the Pittsburgh Sleep Quality Index (PSQI) sebelum (pretest) intervensi back massage adalah $6,28 \pm 1,461$ dan setelah (posttest) intervensi back massage adalah 5,03 $\pm 1,349$ dengan selisih rata-rata $1,241 \pm 0,739$. Pada hasil uji paired sample $t$ test menunjukkan back massage terbukti berpengaruh terhadap kualitas tidur ibu hamil trimester III ( $p$-value $0,000<\alpha 0,05)$.

Kesimpulan: Dengan hasil penelitian ini diharapkan ibu hamil dapat melakukan terapi back massage untuk menurunkan ketegangan, merileksasi tubuh dan meningkatkan kualitas tidur.

Saran Saat ini masih belum ada penyuluhan terkait back massage maka hendaknya bagi tenaga kesehatan dapat memberikan penyuluhan back massage kepada ibu hamil karena back massage telah menjadi bagian dari 
terapi penunjang dalam bidang kesehatan untuk meningkatkan derajat kesehatan terutama dalam meningkatkan kualitas tidur ibu hamil.

Kata Kunci : Kualitas tidur, back massage

\section{PENDAHULUAN}

Proses kehamilan merupakan matarantai yang berkesinambungan yang terdiri dari ovulasi, migrasi spermatozoa dan ovum, konsepsi dan pertumbuhan zigot, nidasi (implantasi) pada uterus, pembentukan plasenta dan tumbuh kembang hasil konsepsi sampai aterm (Manuaba, 2010). Kehamilan sendiri dianggap sebagai sebuah proses normal yang biasa terjadi, namun dalam proses tersebut seringkali muncul berbagai gangguan yang harus ditangani secara hati-hati karena gangguan pada masa kehamilan sendiri merupakan salah satu penyebab meningkatkan angka kematian ibu (Rayyane, 2012).

Pada masa kehamilan, ibu hamil akan mengalami berbagai perubahan pada sistrem reproduksi yang bersifat fisiologis dan terkadang bersifat patologis. Perubahan fisiologis pada ibu hamil seperti peningkatan kadar progesteron dan prolaktin, peningkatan berat badan, gerakan janin, mual-muntah dan distensi kandung kemih berpotensi menyebabkan beberapa gangguan tidur wanita hamil. Selain itu, pada wanita hamil juga sering terjadi nyeri punggung yang juga dapat menyebabkan kualitas tidur yang buruk. Prevalensi nyeri punggung bawah pada wanita hamil hampir terjadi diantara $24 \%$ sampai $90 \%$ wanita hamil. Bahkan, sekitar 20\% wanita hamil mengalami nyeri panggul selama kehamilan yang akan mengganggu kualitas tidur ibu hamil (Hollenbach, et al, 2013).

Sulit tidur atau insomnia merupakan gangguan yang berupa tidur gelisah, kurang tidur atau sama sekali tidak bisa tidur. Kesulitan tidur umumnya lebih banyak dialami pada awal kehamilan. Kemudian keluhan sulit tidur ini akan kembali muncul pada akhir kehamilan. Sulit tidur pada kehamilan selain disebabkan oleh perubahan fisiologis pada sistem reproduksi dapat juga disebabkan oleh masalah psikis seperti perasaan khawatir yang berlebihan dan cemas. Meski nampak remeh, gangguan tidur yang terus menerus akan mengganggu fisik dan kejiwaan ibu hamil (Indiarti, 2012).

Masalah gangguan tidur pada ibu hamil harus diatasi karena jika hal tersebut tidak segera diatasi maka dapat mengganggu aktivitas sehari-hari ibu hamil, dimana ibu hamil menjadi mudah lelah, malas, emosi meningkat dan berakhir dengan stress yang memicu peningkatan kerja jantung sehingga akan meningkatkan risiko terjadinya persalinan premature (Murni, 2009). Jika tidur rata-rata dalam semalam 34 jam bahkan kurang, maka tingkat kekebalan tubuh akan menurun dan mudah mengalami stres (Hawari, 2011). Kualitas tidur yang buruk juga merupakan salah satu faktor risiko terjadinya peningkatan tekanan darah. Dalam kaitannya dengan tekanan darah, stres dapat meningkatkan resistensi vaskular perifer dan curah jantung serta menstimulasi aktivitas sistem saraf simpatis (Black \& Hawk, 2014). Penelitian yang dilakukan Kathryn et al., (2004) menggunakan studi prospective observational dari 131 wanita hamil trimester tiga ditemukan bahwa wanita hamil dengan durasi tidur terganggu memiliki risiko persalinan lama dan beresiko untuk kelahiran sesar (Lee et al., 2004).

Salah satu upaya yang dapat dilakukan untuk mengatasi gangguan tidur pada masa kehamilan adalah dengan terapi nonfarmakologi diantaranya menggunakan terapi back massage (pijat punggung). Terapi pijat merupakan intervensi nonfarmakologis yang paling sering direkomendasikan pada wanita hamil selain dari terapi-terapi yang lain. Massage atau pijat merupakan tindakan yang dilakukan dengan tekanan tangan pada jaringan lunak, tanpa menyebabkan gerakan atau perubahan posisi sendi untuk menghasilkan relaksasi dan atau memperbaiki sirkulasi (Maryunani, 2010). Penelitian yang dilakukan Field et al menunjukkan bahwa terapi massage terbukti dapat menurunkan kecemasan, meningkatkan mood dan kualitas tidur, dan mengurangi nyeri punggung (Hollenbach, et al, 2013). Penelitian yang dilakukan Ko \& Lee (2014) tentang efektifivitas penggunaan back massage terhadap kualitas tidur ibu pospartum menunjukkan bahwa pada hasil pengukuran kualitas tidur menggunakan Pittsburgh Sleep Quality Index (PSQI) didapatkan skor mean PSQI pada kelompok intervensi secara signifikan lebih rendah ( $B=-3.97$, standar error $=0,43, p 0,000<0,001$ ) dibandingkan kelompok kontrol atau dengan kata lain pemberian pijat punggung (back massage) secara signifikan mampu meningkatkan kualitas tidur. Penelitian Atika (2013) yang dilakukan terhadap ibu hamil trimester III dengan menggunakan uji wilxocon test menunjukkan bahwa back massage terbukti efektif untuk meningkatkan kualitas tidur ibu hamil trimester III (p-value 0,005< $\alpha 0,05$ ). 


\section{METODOLOGI}

Jenis penelitian ini adalah kuantitatif, Dengan desain yaitu pre experiment designs (pra esksperimen) dengan rancangan one group pretest posttest. Dalam rancangan ini tidak ada kelompok pembanding (kontrol) tetapi dilakukan observasi pertama (pretest) yang memungkinkan peneliti dapat menguji perubahan yang terjadi setelah adanya perlakuan (program) (posttest). Penelitian ini dilaksanakan di BPM Tiara Iswantika Wonosari Kecamatan Pekalongan Kabupaten Lampung Timur

Populasi dalam penelitian ini adalah seluruh ibu hamil trimester III, Pengambilan sampel dalam penelitian ini menggunakan teknik accidental sampling. Adapun sampel yang didapatkan adalah sebanyak 29 orang dengan kriteria eksklusi lbu hamil yang mengalami gangguan kehamilan

Pada penelitian ini, untuk mengukur kualitas tidur digunakan kuesioner the Pittsburgh Sleep Quality Index (PSQI) yang dikembangkan oleh Buyssee. Analisa data menggunakan uji statistik parametrik uji T berpasangan (Paired T Test).

\section{HASIL PENELITIAN \\ Karakteristik Responden}

Tabel 1.

Karakteristik Responden

\begin{tabular}{lcc}
\hline Karakteristik & Frekuensi & Presentase (\%) \\
\hline Paritas & & \\
Primigravida & 14 & 48,3 \\
Multigravida & 15 & 51,7 \\
Pendidikan & & \\
Sarjana & 4 & 13,8 \\
SMA & 21 & 72,4 \\
SMP & 4 & 13,8
\end{tabular}

\begin{tabular}{lcc} 
Pekerjaan & & \\
IRT & 23 & 79,4 \\
Pedagang & 3 & 10,3 \\
PNS & 3 & 10,3 \\
\hline
\end{tabular}

Berdasarkan table 1 dapat diketahui bahwa dari 29 responden, sebagian besar adalah primigravida yaitu sebanyak 15 orang $(51,7 \%)$, dan multigravida adalah sebanyak 14 orang $(48,3 \%)$. Dilihat dari tingkat pendidikan formal yang ditempuh responden, sebagian besar adalah lulus pada jenjang pendidikan SMA yaitu sebanyak 21 orang $(72,4 \%)$, sedangkan sarjana dan SMP masingmasing 4 orang $(13,8 \%)$. Sedangkan dilihat dari status pekerjaan maka, sebagian besar responden adalah ibu rumah tanggal yaitu sebanyak 23 orang $(79,3 \%)$, sedangkan responden yang bekerja sebagai pedagang dan PNS masing-masing terdapat 3 orang $(10,3 \%)$.

Pada Tabel 2. dibawah rata-rata skor kualitas tidur ibu hamil pada hasil pengukuran menggunakan kuesioner the Pittsburgh Sleep Quality Index (PSQI) sebelum (pretest) intervensi back massage adalah $6,28 \pm 1,461$ atau termasuk dalam kategori buruk, skor minimum hasil pengukuran kualitas tidur adalah 4 dan maksimum 9. Pada confidence interval 95\% diyakini bahwa rata-rata skor kualitas tidur ibu hamil sebelum intervensi back massage adalah antara 5,72 sampai dengan 6,83 . Rata-rata skor kualitas tidur ibu hamil pada hasil pengukuran menggunakan kuesioner the Pittsburgh Sleep Quality Index (PSQI) setelah (posttest) intervensi back massage adalah $5,03 \pm 1,349$ atau termasuk dalam kategori baik, skor minimum hasil pengukuran kualitas tidur adalah 3 dan maksimum 8. Pada confidence interval $95 \%$ diyakini bahwa rata-rata skor kualitas tidur ibu hamil setelah intervensi back massage adalah antara 4,52 sampai dengan 5,55 .

Tabel 2.

Kulaitas Tidur

\begin{tabular}{ccccc}
\hline Variabel & Mean & SD & $\begin{array}{c}\text { Minimum- } \\
\text { Maksimum }\end{array}$ & Cl; 95\% \\
\hline $\begin{array}{c}\text { Kualitas tidur ibu hamil sebelum (pretest) } \\
\text { intervensi back massage }\end{array}$ & 6,28 & 1,461 & $4-9$ & $5,72-6,83$ \\
$\begin{array}{c}\text { Kualitas tidur ibu hamil setelah (posttest) } \\
\text { intervensi back massage }\end{array}$ & 5,03 & 1,349 & $3-8$ & $4,52-5,55$ \\
\hline
\end{tabular}

Tabel 3.

Back Massage Pada Kualitas Tidur 


\begin{tabular}{cccccc}
\hline Variabel & Mean & \multirow{2}{*}{ SD } & \multicolumn{2}{c}{ Cl; 95\% } & \multirow{2}{*}{ Lower } \\
& difference & Upper & -value \\
\hline $\begin{array}{c}\text { Kualitas tidur ibu hamil sebelum (pretest) dan } \\
\text { setelah (posttest) intervensi back massage }\end{array}$ & 1,241 & 0,739 & 0,960 & 1,523 & 0,000 \\
\hline
\end{tabular}

Rata-rata kualitas tidur ibu hamil trimester III antara sebelum (pretest) dan setelah (posttest) intervensi back massage adalah 1,241 $\pm 0,739$. Pada confidence interval 95\% diyakini bahwa jika diberlakukan pada populasi maka selisih skor ratarata antara sebelum dan setelah terapi relaksasi back massage berada pada rentang 0,960 sampai dengan 1,523. Hasil uji statistik paired sample t-test didapatkan $p$-value $0,000(p<\alpha 0,05)$ maka dapat disimpulkan bahwa terdapat perbedaan bermakna rata-rata kualitas tidur ibu hamil trimester III antara sebelum dan setelah pemberian terapi back massage, artinya secara statistik terbukti ada pengaruh back massage terhadap kualitas tidur ibu hamil trimester III, dimana skor kualitas tidur ibu hamil trimester III sebelum pemberian terapi back massage lebih tinggi secara bermakna dibandingkan sesudah terapi back massage.

\section{PEMBAHASAN}

Hasil penelitian menunjukkan bahwa rata-rata skor kualitas tidur ibu hamil trimester III pada hasil pengukuran menggunakan kuesioner the Pittsburgh Sleep Quality Index (PSQI) sebelum (pretest) intervensi back massage adalah 6,28 $\pm 1,461$, skor minimum hasil pengukuran kualitas tidur adalah 4 dan maksimum 9. Pada confidence interval 95\% diyakini bahwa rata-rata skor kualitas tidur ibu hamil sebelum intervensi back massage adalah antara 5,72 sampai dengan 6,83 .

Hasil penelitian menunjukkan bahwa rata-rata skor kualitas tidur ibu hamil pada hasil pengukuran menggunakan kuesioner the Pittsburgh Sleep Quality Index (PSQI) setelah (posttest) intervensi back massage adalah $5,03 \pm 1,349$, skor minimum hasil pengukuran kualitas tidur adalah 3 dan maksimum 8. Pada confidence interval $95 \%$ diyakini bahwa rata-rata skor kualitas tidur ibu hamil setelah intervensi back massage adalah antara 4,52 sampai dengan 5,55 .

Hasil analisis uji statistik paired sample t-test menunjukkan bahwa selisih skor rata-rata kualitas tidur ibu hamil trimester III antara sebelum (pretest) dan setelah (posttest) intervensi back massage adalah 1,241 $\pm 0,739$ dengan $p$-value $0,000(p<\alpha$ $0,05)$ maka dapat disimpulkan bahwa terdapat perbedaan bermakna rata-rata kualitas tidur ibu hamil trimester III antara sebelum dan setelah pemberian terapi back massage, artinya secara statistik terbukti ada pengaruh back massage terhadap kualitas tidur ibu hamil trimester III, dimana skor kualitas tidur ibu hamil trimester III setelah pemberian terapi back massage lebih rencah secara bermakna dibandingkan sesudah terapi back massage.

Hasil penelitian ini sesuai dengan teori yang dikemukakan oleh Nurgiwiyati, (2015) bahwa pijatan dapat menstimulasi pengeluaran zat kimiawi dalam tubuh seperti serotonin atau endorphin. Terapi pijat merupakan terapi dengan pendekatan holistic yang berfungsi menurunkan tekanan darah, denyut jantung, memperbaiki pernafasan, dan meningkatkan aliran kelenjar limphe ke dalam saluran pembuluh darah dan membantu pengeluaran sisa metabolisme dan mengurangi kekakuan, menjadikan tubuh menjadi rilek dan meningkatkan kualitas tidur dan memperbaiki kesehatan pada umumnya.

Hasil penelitian ini sejalan dengan penelitian yang dilakukan oleh Ko \& Lee (2014) tentang (Randomised controlled trial of the effectiveness of using back massage to improve sleep quality among Taiwanese insomnia postpartum women) menunjukkan bahwa pada hasil pengukuran kualitas tidur menggunakan Pittsburgh Sleep Quality Index (PSQI) didapatkan skor mean PSQI pada kelompok intervensi secara signifikan lebih rendah ( $B=-3.97$, standar error $=0,43, p$-value $0,000<0,001)$ dibandingkan kelompok kontrol atau dengan kata lain pemberian pijat punggung (back massage) secara signifikan mampu meningkatkan kualitas tidur. Penelitian Atika (2013) yang dilakukan terhadap ibu hamil trimester III dengan menggunakan uji wilxocon test juga menunjukkan bahwa back massage terbukti efektif untuk meningkatkan kualitas tidur ibu hamil trimester III ( $p$-value $0,005<\alpha 0,05)$.

Berdasarkan uraian hasil penelitian di atas maka dapat dijelaskan bahwa terapi back massage terbukti signifikan dalam meningkatkan kualitas tidur ibu hamil hal ini dapat terjadi karena back massage membantu memperlancar metabolisme dalam tubuh sehingga aliran oksigen dalam darah meningkat dan memicu pengeluaran hormone endorphin yang merupakan zat kimia endogen (diproduksi oleh tubuh) yang terstruktur serupa dengan opioid (juga disebut sebagai opiat atau narkotik). Apabila tubuh mengeluarkan subtansi-substansi ini maka salah 
satu efeknya adalah memberikan rasa nyaman, senang, dan rileks sehingga mampu memperbaiki psikologis dan ketegangan ibu hamil yang pada akhirnya mampu meningkatkan kualitas tidur bagi ibu hamil. Oleh karena itu, back massage dapat menjadi bagian dari terapi alternatif ataupun komplementer yang masuk dalam sistem pelayanan kesehatan khususnya untuk membantu meningkatkan kualitas tidur bagi ibu hamil terutama pada trimester ketiga.

\section{KESIMPULAN}

Terdapat pengaruh Back massage terhadap kualitas tidur ibu hamil trimester III ( $p$-value $0,000<\alpha 0,05)$ dengan selisih skor rata-rata antara sebelum dan setelah intervensi 1,241 $\pm 0,739(\mathrm{Cl}$; $95 \%$ 0,960-1,523).

\section{SARAN}

Saat ini masih belum ada penyuluhan terkait back massage maka hendaknya bagi tenaga kesehatan dapat memberikan penyuluhan back massage kepada ibu hamil karena back massage telah menjadi bagian dari terapi penunjang dalam bidang kesehatan untuk meningkatkan derajat kesehatan terutama dalam meningkatkan kualitas tidur ibu hamil.

\section{DAFTAR PUSTAKA}

Atika, A. F., Wahyuni, S., \& Santoso, T. B. (2013). Pengaruh Back Massage Terhadap Kualitas Tidur Pada Ibu Hamil Trimester Tiga (Doctoral dissertation, Universitas Muhammadiyah Surakarta).

Black, J. M., \& Hawks, J. H. (2014). Keperawatan medikal bedah: manajemen klinis untuk hasil yang diharapkan. Elsevier (Singapore).

Fajar, Rianti (2017). Pentingnya Tidur Cukup bagi Ibu Hamil. Artikel. Info Kesehatan, diakses pada 17 Maret 2018 dalam web site: http://www.1 health.id/id/article/category/ibu- dan-anak/pentingnya-tidur-cukup-bagi-ibuhamil.html

Hawari, Dadang. (2011). Manajemen Stres, Cemas dan Depresi. Jakarta: Fakultas Kedokteran Universitas Indonesia.

Hollenbach, D., Broker, R., Herlehy, S., \& Stuber, K. (2013). Non-pharmacological interventions for sleep quality and insomnia during pregnancy: a systematic review. The Journal of the Canadian Chiropractic Association, 57(3), 260.

Indiarti, M.T (2012) Panduan Klinis Paling Komplit Kehamilan, Persalinan, dan Perawatan bayi. Jakarta: PT. Buku Seru

Joshgant (2016) Back Massage during Pregnancy. Artikel diakses pada 17 Maret 2018 dalam web site: http://www.newkidscenter.com/BackMassage-During-Pregnancy.html

Ko, Y. L., \& Lee, H. J. (2014). Randomised controlled trial of the effectiveness of using back massage to improve sleep quality among Taiwanese insomnia postpartumwomen. Midwifery, 30(1), 60-64.

Lee, K. A., \& Gay, C. L. (2004). Sleep in late pregnancy predicts length of labor and type of delivery. American journal of obstetrics and gynecology, 191(6), 2041-2046.

Manuaba, I. B. G. (2010). IImu kebidanan, penyakit kandungan dan keluarga berencana. Jakarta: EGC, 15, 157.

Maryunani, A. (2010). Nyeri dalam persalinan "teknik dan cara penanganannya". Jakarta: Trans info media.

Murni, W. (2009). Kiat mengatasi masalah kehamilan dan janin. Yogyakarta: Elmatera Publishing.

Nurgiwiyati, W. (2015) Terapi Alternatif dan Komplementer Dalam Bidan Keperawatan. Bogor: In Media

Rayyane. P (2012) Panduan Kehamilan Untuk calon Ibu. Yogyakarta: Imperium 